\title{
Drought as an analogue climate change scenario for prediction of potential impacts on Malawi's wildlife habitats
}

\author{
Francis X. M kanda* \\ Department of National Parks and Wildlife, PO Box 30131, Lilongwe 3, Malawi
}

\begin{abstract}
This study compares precipitation and temperature from recent drought episodes with general circulation model outputs to examine the likely effects of climate change on herbaceous layer productivity, ground cover, and forage utilization in M alawi's Lengwe National Park. There are no differences in precipitation distribution and temperature during the drought episodes and climate change scenarios. The implication is that deteriorating habitat conditions such as those observed during the drought incidents might occur under climate change. Herbacious layer productivity was 2 to 6 times lower than in a normal year; ground cover was reduced to $22-32 \%$; and the number of intensely browsed plants increased significantly (chi-square $=10.5, p=0.01$ ) as the drought progressed. Consequently, it is unlikely that the degraded habitat would support large mammal populations in Lengwe specifically, or in Malawi in general.
\end{abstract}

KEY WORDS: Precipitation · Temperature · Productivity · Ground cover · Browse utilisation

\section{INTRODUCTION}

Severe drought incidents have afflicted wildlife in southern Africa, including Malawi. Their impacts have been variable, but certainly harmful. Kamvazina (1981) reported that the drought of 1980 resulted in poor regeneration of vegetation and nyala Tragelaphus angasi Gray mortality in Lengwe National Park, Malawi. Similar effects of the drought occurred in wildlife conservation areas in Botswana and South Africa (Walker et al. 1987) and in Zimbabwe (M agadza 1994).

The temperatures predicted by general circulation models (GCMs) under climate change are higher than those found during the droughts (M agadza 1994). However, Magadza (1994) reported that recent comparisons of GCM control runs and observed climate have shown that models (GFDL, GISS, UK) tend to underestimate current temperatures in some regions of southern Africa while overestimating precipitation. An assessment of the impacts of global climate change on

*E-mail: nrmp-lib@malawi.net
Malawi wildlife was done by Mkanda (1996) using climate change scenarios and the habitat suitability model developed by the US Fish and Wildlife Service in 1981. The study suggested that ungulates in Lengwe National Park would be susceptible to climate-induced changes in habitat and food supply. The problem with modelling habitat suitability using climate change scenarios, however, is that the model outputs cannot be validated, as suitable methods are not yet available. A second problem is that models may not necessarily reflect the actual magnitude of future ecosystem change (Carter et al. 1994, Hulme 1996). Previous drought episodes, on the other hand, can act as analogue climate change scenarios because the observed effects can be used to project the likely impacts of climate change.

The uncertainty surrounding predictions of global climate change by models, and hence the inability to deduce from the models what the impacts of climate change on wildlife habitats are likely to be, leads to the following question: Will the impacts be worse than those observed during the recent drought episodes? To address this question, this study examined some 
climate and wildlife habitat variables during drought events in Lengwe National Park.

\subsection{Study site}

Lengwe National Park, which lies at $34^{\circ} 35^{\prime} \mathrm{E}, 16^{\circ} 15^{\prime} \mathrm{S}$ in the Lower Shire Valley in southern Malawi, was selected as the study site. There are 2 advantages to using Lengwe as a study site. The first one is the availability of some records of drought episodes and their consequences. Second, the area is apparently vulnerable to drought; hence, using it as a case study gives an insight into the potential effects of climate change on wildlife habitats in Malawi.

The park has a semi-arid type of climate (Anonymous 1975). The minimum temperature is $14.3^{\circ} \mathrm{C}$ in $\mathrm{J}$ une, while the maximum is $35.8^{\circ} \mathrm{C}$ in November. Monthly mean precipitation ranges from $5 \mathrm{~mm}$ in September to $167 \mathrm{~mm}$ in December, while the annual rainfall is $751 \mathrm{~mm}$. The rainy season lasts from November to April, but small amounts of precipitation called Chiperoni are brought by high-pressure southeasterly winds from M ay to J uly (M kanda 1996).

Acacia thicket clump savannah is the dominant vegetation in Lengwe. The common ungulates include buffalo Syncerus caffer, kudu Tragelaphus strepsiceros, warthog Phachoecorus aethiopicus, impala Aepyceros melampus. Reptiles, small mammals, and birds are common. The nyala is the keystone species in the park, numbering about 2000 in 1992.

\section{MATERIALS AND METHODS}

To assess the likely impacts of global climate change on wildlife habitat, the study compared precipitation and temperature from the drought of 1979/80 (Drought 1) and 1991/92 (Drought 2) with GCM scenarios. Herbaceous layer productivity, ground cover, and forage utilisation by browsers during Drought 2 were measured, and inferences were made as to the likely response of these habitat variables to climate change.

2.1. Climate scenarios. Mean monthly precipitation and ambient temperature data came from the M eteorological Department (hereafter as ' $M$ wM et') database for the period 1961-1990. Data from 3 sites close to Lengwe National Park - namely, Makhanga, Mangochi, and Salima at $35^{\circ}$ $10^{\prime} \mathrm{E}, 16^{\circ} 30^{\prime} \mathrm{S} ; 35^{\circ} 16^{\prime} \mathrm{E}, 14^{\circ} 29^{\prime} \mathrm{S}$; and $34^{\circ}$ $35^{\prime} \mathrm{E}, 13^{\circ} 45^{\prime} \mathrm{S}$, respectively-were averaged and considered as the baseline (existing climate) scenario for the study area.

As part of technical support, the US Country Studies Program supplied the following
4 GCM outputs: Canadian Climate Centre (CCC) model (Boer et al. 1992); GFD3 model from the Geophysical Fluid Dynamic Laboratory (Manabe \& Wetherald 1987); and United Kingdom M eteorological Office UK89 model (Mitchell et al. 1989).

Baseline climate scenarios were developed from these outputs following Unganai (1996). As done with the M wMet data, precipitation and temperature outputs from 3 grid points (Table 1 ) close to the study area were averaged for each model. The averages served as baseline scenarios. The mean model outputs and the spatially averaged $\mathrm{M}$ wM et precipitation and temperature data were compared to facilitate selection of GCMs that closely simulated the seasonal patterns of the current climate in Malawi. Three GCMs-GFD3, UK89, and CCC - appeared useful in simulating the current climate in the study area (Figs. $1 \& 2$ ).

To develop climate change scenarios, changes in ambient temperature patterns were analysed in comparison with the existing climate patterns as described by Unganai (1996). The ambient temperature changes were computed from the difference of the baseline and climate change scenarios from the GCM outputs. Precipitation pattern changes were computed as the ratio of the baseline to climate change outputs.

2.2. Comparisons of drought with climate scenarios. Temperature and precipitation were recorded by the park research unit during the drought events, while evaporation was only recorded during Drought 2. Magadza (1994) showed that during the 1991/92 drought in Zimbabwe, evaporation exceeded precipitation throughout the cropping season from December to $M$ arch while during normal seasons precipitation exceeds evaporation. To determine if this trend applied to the study area, the precipitation and evaporation data were plotted (Fig. 3). Besides the annual totals, precipitation distribution in terms of amount $\left(\mathrm{mm} \mathrm{d}^{-1}\right)$ was considered (Fig. 4). Experience has shown that, in Lengwe, precipitation that is distributed over the seasons is more crucial in sustaining forage production than large quantities received only at the beginning of the rainy season.

Mean precipitation and temperature for the current climate (M wMet), drought episodes, and GCM baseline scenarios were calculated. To test if there were significant differences between the different data sets,

Table 1. Selected grid points for generation of climate scenarios, Lengwe National Park

\begin{tabular}{|c|c|c|c|}
\hline GCM & & Grid points & \\
\hline $\mathrm{CCC}$ & $30.00^{\circ} \mathrm{E}, 16.70^{\circ} \mathrm{S}$ & $33.75^{\circ} \mathrm{E}, 16.70^{\circ} \mathrm{S}$; & $37.75^{\circ} \mathrm{E}, 16.70^{\circ} \mathrm{S}$ \\
\hline GFD3 & $30.00^{\circ} \mathrm{E}, 16.77^{\circ} \mathrm{S}$ & $33.75^{\circ} \mathrm{E}, 16.77^{\circ} \mathrm{S}$; & $37.50^{\circ} \mathrm{E}, 16.77^{\circ} \mathrm{S}$ \\
\hline UK89 & $31.88^{\circ} \mathrm{E}, 16.25^{\circ} \mathrm{S} ;$ & $35.63^{\circ} \mathrm{E}, 16.25^{\circ} \mathrm{S} ;$ & $39.38^{\circ} \mathrm{E}, 16.25^{\circ} \mathrm{S}$ \\
\hline
\end{tabular}




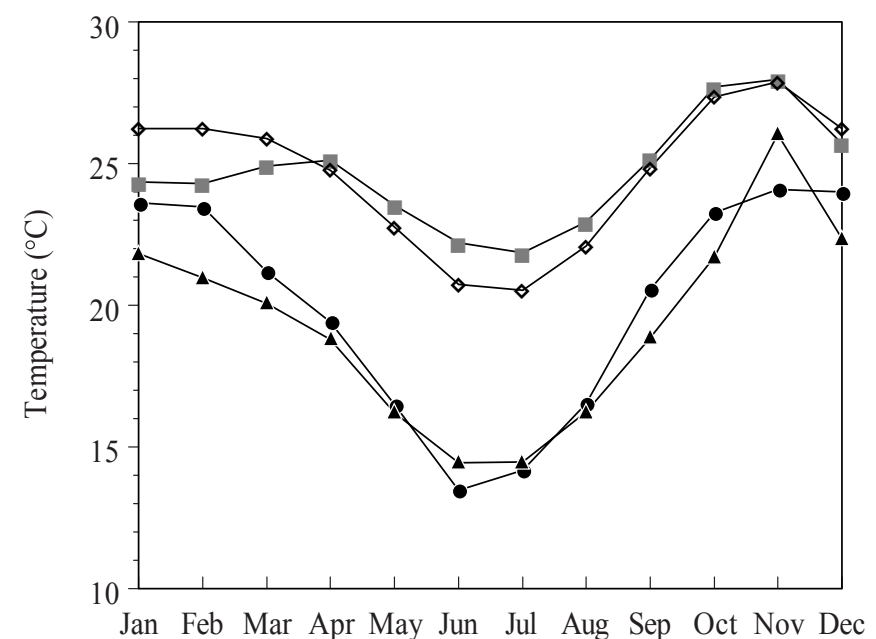

Months

$\diamond$ MwMet $\wedge \mathrm{CCCM} \backsim \mathrm{GFD} 3 \bullet \mathrm{UK} 89$

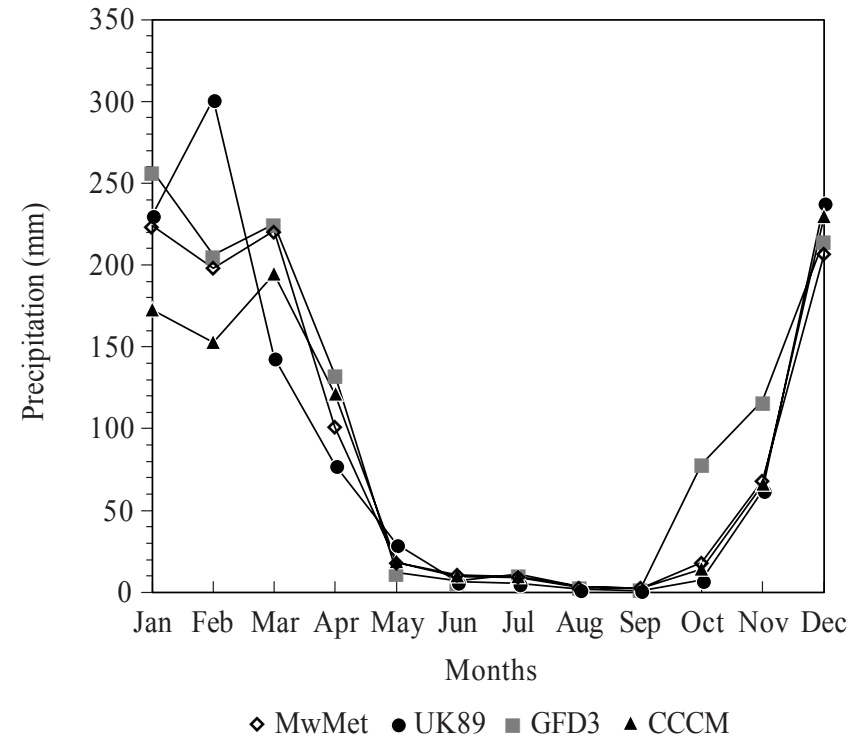

Fig. 1. Ambient temperature and precipitation pattern, MwM et and GCM baseline scenarios, Lengwe National Park, Malawi (baseline scenario)
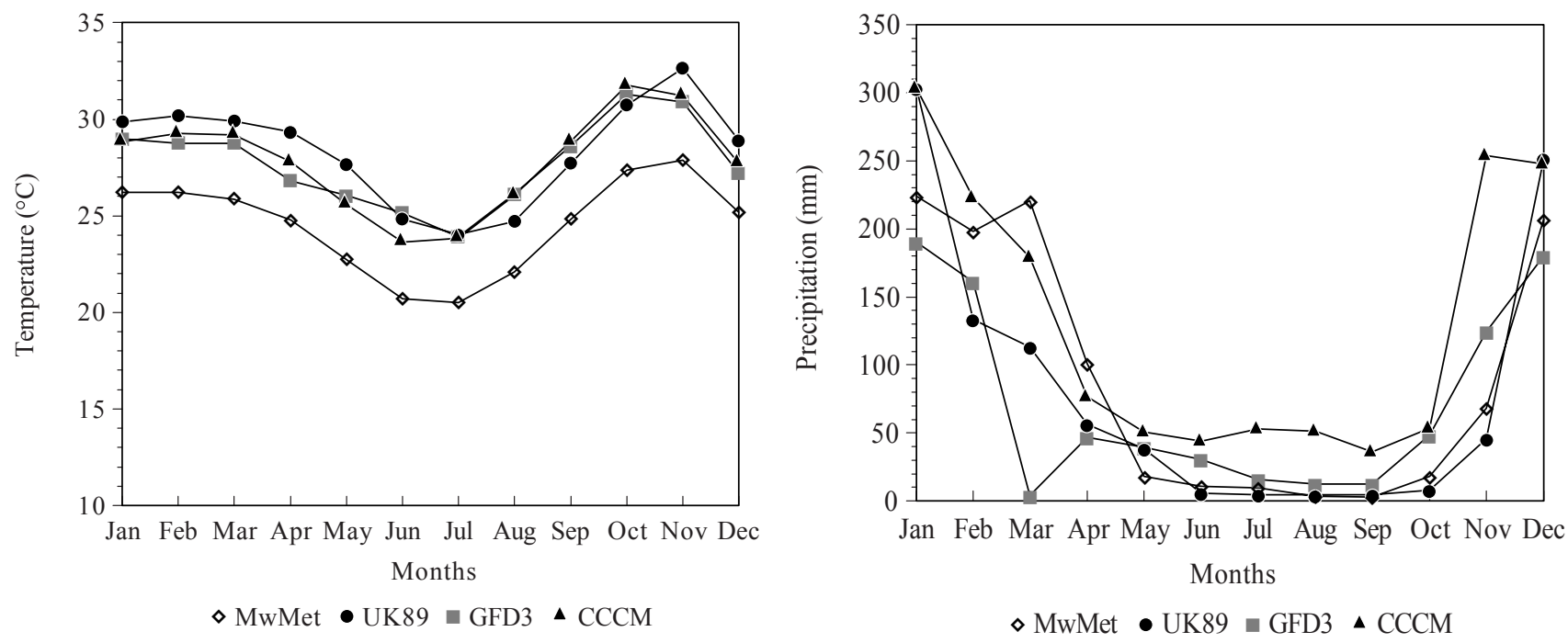

Fig. 2. Ambient temperature and precipitation pattern, MwM et and GCM climate change scenarios, Lengwe National Park (climate change scenario)

Dunnett's method of means comparison with a control (Sall \& Lehman 1996) was employed. The tests were as follows: (1) MwM et versus the drought episodes and baseline scenarios, the M wM et data acting as the control because the assumption is that the current climate is optimally suitable (M kanda 1996); (2) M wM et compared with climate change scenarios; and (3) Drought 2 against Drought 1 and climate change scenarios, using Drought 2 as the control because it was described as the worst in living memory (Magadza 1994).

2.3. Herbaceous layer productivity and off-take. Walker et al. (1987) reported that grass productivity, which is part of the herb layer productivity, was drastically reduced in the Tuli block (Botswana) during the drought of $1980 / 81$. Therefore this study found it imperative to measure herbaceous layer productivity and off-take by mammals and harvester termites Hodotermes mossambicus Hagen.

The rainy season for Drought 2 (November 1991 to April 1992) was subdivided according to Mkanda \& Munthali (1991) - that is, early rains (N ovember to J anuary), and late rains (February to A pril). Productivity and off-take were assessed in two $5 \times 5 \mathrm{~m}$ exclosures that the Lengwe Research Unit established in 1986 in 


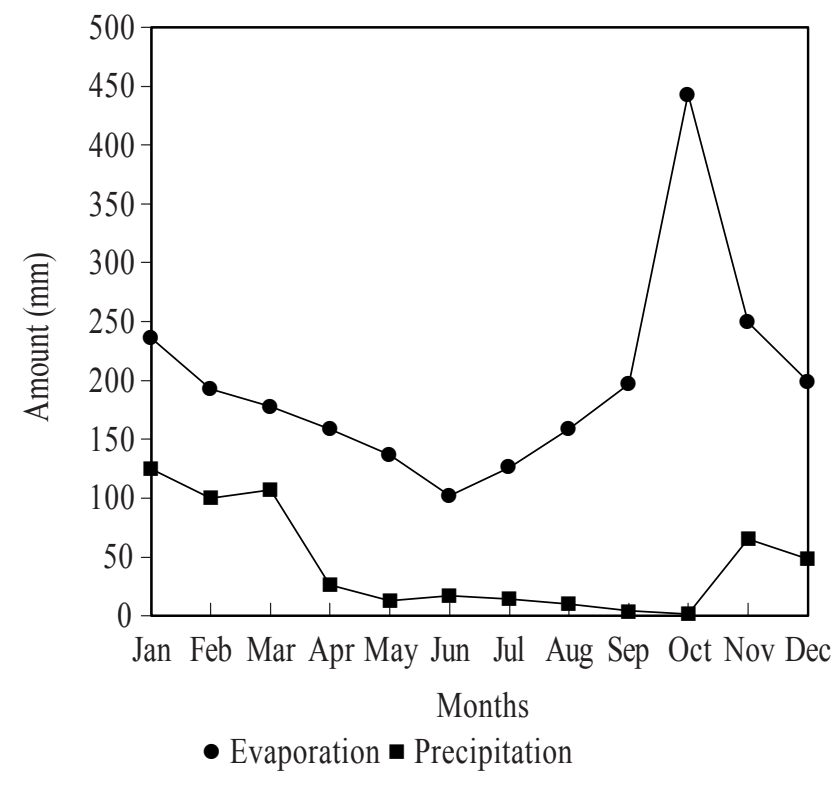

Fig. 3. Precipitation and evaporation during Drought 2 (1991/92), Lengwe National Park

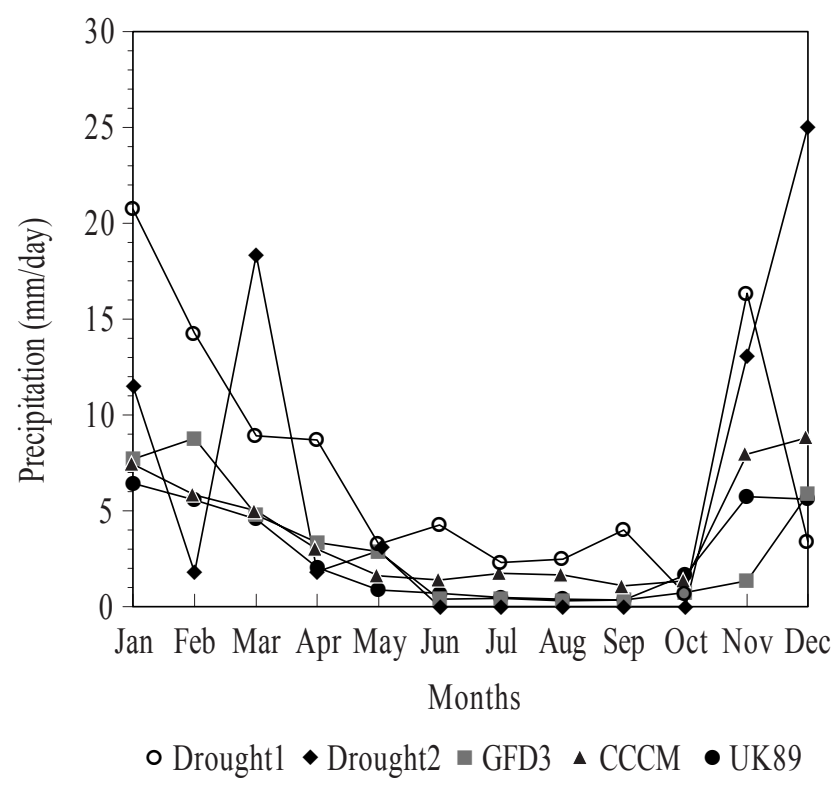

Fig. 4. Precipitation distribution for drought episodes and GCM climate change scenarios, Lengwe National Park. Drought 1: 1979/80; Drought 2: 1991/92

Acacia nigrescens and Albizia harveyi/Ziziphus mucronata vegetation communities. These vegetation communities generally support high animal biomass and are some of the favourite nyala (keystone species) habitats (M unthali 1991). Samples were clipped inside and outside the exclosures in the late rainy season when productivity was at its peak. Productivity was calculated as $\mathrm{kg}$ of dry matter per hectare. The differ- ence between the inside and outside of the exclosures reflected the off-take by harvester termites, as well as grazing and trampling by ungulates. The results were compared with those obtained during normal seasons, for example, 1989 and 1990.

2.4. Ground cover. In contrast with herb layer productivity monitoring, the park did not have a ground cover monitoring program. Therefore, data were collected during Drought 2 only.

To determine if there was a trend in ground cover as the drought progressed, sampling took place in the late rainy season and early dry season (May to J uly). Poor accessibility precluded sampling during early rains, while funding constraints hindered sampling during the late dry season (August to October).

Forty-four clearly marked sampling stations were established at $1 \mathrm{~km}$ intervals along the road network (61 km long) during the late rains in 1992. Because of poor accessibility, the stations covered only 9 of the 20 vegetation types described by Hall-M artin (1972). The vegetation included the preferred habitats of nyalathat is, Pterocarpus lucens shrub thickets, Acacia nigrescens thicket clump savannah, and Acacia harveyi/Ziziphus mucronata thicket clump. The herbaceous vegetation cover was assessed using the lineintercept technique (Mueller-Dombois \& Ellenberg 1974). At each station, a $10 \mathrm{~m}$ line was set, and the basal length of the herbaceous stratum beneath the line was recorded. The basal cover was calculated as the percentage of the line intercepted by the basal portions of herbaceous plants. A basal cover of $<40 \%$ was arbitrarily considered as low since there were no previous data for comparison. The relative frequency of occurrence of the intercepts and bare ground in each vegetation community was determined and averaged for all the vegetation communities. An unpaired t-test was applied to detect any differences in basal cover between the late rains and early dry season.

2.5. Browse utilisation. Since the park has browsers such as kudu, bushbuck Tragelaphus scriptus, and nyala, it was essential to elucidate their impact, through browsing, on woody plant growth. The main factor considered was the intensity of browsing.

Sampling took place in the same vegetation communities where ground cover was assessed. For the reasons given above, the assessment was al so confined to the late rainy and early dry seasons. Sampling was done at $500 \mathrm{~m}$ intervals using the Point Centred Quarter method (M ueller-Dombois \& Ellenberg 1974). Each sampling station was positioned $100 \mathrm{~m}$ away from the road as it was assumed that animal activity increased with distance from the road. The number and height of woody plants that were nearest to the sampling point were recorded and categorised according to browsing impact by modifying the method used by Vesey- 
FitzGerald (1973) as follows: (1) b0 =zero browsing; no sign of browsing; (2) b1 = light browsing; evidence of browsing apparent, but the impact is replaceable by the season's growth; the leaves are browsed but branches or twigs are intact; (3) b2 =intense browsing; leaves browsed, branches or twigs are broken; and (4) b3 =severe and damaging browsing; stems broken, individual plants may be disfigured so that their chances of survival are reduced.

The number of plants in each browse category was grouped by season to determine the trend in browsing impact. To detect any differences in browsing impact, Dunnett's method was used, b0 acting as the control. To detect if the changes in browsing impact between the seasons were significant, Pearson's chi-square test (Sall \& Lehman 1996) was used.

\section{RESULTS}

\subsection{C urrent climate simulation by climate scenarios}

Overall, the GCM s predict seasonal trends of annual precipitation and ambient temperature that are similar to the existing climatic conditions (Figs. $1 \& 2$ ). As reported by M kanda (1996), the general trend is frequent precipitation at the onset of the rainy season in November, continuing until J anuary. The Chiperoni rains take over in winter ( $M$ ay to J uly). Ambient temperatures are usually above $25^{\circ} \mathrm{C}$ during most of the year except between $\mathrm{M}$ ay and August, when they decline below $20^{\circ} \mathrm{C}$. Although the UK89 and CCC

Table 2. Changes (differences between baseline and climate change) in precipitation and ambient temperature under 3 climate change scenarios, Lengwe National Park

\begin{tabular}{|lcc|}
\hline GCM & $\Delta$ temperature $\left({ }^{\circ} \mathrm{C}\right)$ & $\Delta$ precipitation $(\%)$ \\
\hline UK89 & 3.8 & 2.11 \\
GFD3 & 3.1 & 17.23 \\
CCC & 3.2 & -8.26 \\
\hline
\end{tabular}

models also simulate the seasonality of the temperature, they predict lower ambient temperatures than the existing temperatures and those predicted by the GFD3 model (Fig. 1).

\subsection{Comparison of current climate with drought and baseline climate scenarios}

The mean annual precipitation was lower during Drought 1 and Drought 2 than found for $\mathrm{MwM}$ et. The GFD3 and UK89 models predict an increase over the current precipitation (M wM et) (Tables $2 \& 3$ ). Only the CCC model implies a decline $(-8 \%)$ in annual precipitation under climate change, while the GFD3 model shows a higher expected increase in precipitation than the UK89 model. However, the differences in mean annual precipitation between $\mathrm{MwM}$ et and the Drought 1, Drought 2, and the baseline climate change scenarios are not significant (Table 4).

All GCM scenarios suggest that ambient temperatures will rise within the study area; the temperature increases range from 3.1 to $3.8^{\circ} \mathrm{C}$ (Table 2). The UK89 and CCC models predict significant increases in mean temperatures under the climate change scenario relative to the current mean temperatures (Table 5).

$M$ ean temperatures under current ( $\mathrm{M}$ wM et) climate conditions are significantly higher than predicted by the UK89 and CCC models (Tables $3 \& 5$ ), almost the same as suggested by the GFD3 model, but lower than found during the drought events. The differences in mean temperatures recorded during the 2 drought incidents are not significant (Table 5).

\subsection{Comparison of drought with climate change scenarios}

The mean annual precipitation under the 2 drought episodes was lower than projected by the GCM scenarios, Drought 2 having the lowest amount (Table 3). However, the differences are not significant (Table 4).

Table 3. Annual means of precipitation and ambient temperature under MwMet, drought, and climate change scenarios, Lengwe National Park

\begin{tabular}{|c|c|c|c|c|c|}
\hline \multirow[t]{2}{*}{ Scenario } & \multicolumn{2}{|c|}{ Baseline scenario } & \multicolumn{3}{|c|}{ Climate change scenario } \\
\hline & Precipitation $(\mathrm{mm})$ & Temperature $\left({ }^{\circ} \mathrm{C}\right)$ & Precipitation $(\mathrm{mm})$ & Precipitation $\left(\mathrm{mm} \mathrm{d}^{-1}\right)$ & Temperature $\left({ }^{\circ} \mathrm{C}\right)$ \\
\hline $\mathrm{CCC}$ & 131.0 & 19.3 & 82.7 & 3.9 & 27.8 \\
\hline UK89 & 80.8 & 20.0 & 92.0 & 2.9 & 28.4 \\
\hline GFD3 & 72.1 & 24.6 & 105.7 & 3.1 & 27.7 \\
\hline Drought 1 & 44.2 & 25.7 & - & - & - \\
\hline Drought 2 & 29.9 & 26.3 & - & - & - \\
\hline M wM et & 90.1 & 24.6 & - & - & - \\
\hline
\end{tabular}


Table 4. Dunnett's values from precipitation mean comparisons at the $99 \%$ level, Lengwe National Park. Negative values: pairs are not significant

\begin{tabular}{|c|c|c|c|}
\hline Scenario & $\begin{array}{l}\text { Baseline scenario control } \\
\qquad \mathrm{MwM} \text { et }\end{array}$ & $\begin{array}{c}\text { Climate change } \\
\text { Drought } 2\end{array}$ & $\begin{array}{l}\text { enario control } \\
\text { M wM et }\end{array}$ \\
\hline $\mathrm{CCC}$ & -63.4 & -55.9 & -115.2 \\
\hline UK89 & -94.8 & -46.6 & -120.7 \\
\hline GFD3 & -86.2 & -33.0 & -107.1 \\
\hline Drought 1 & -58.3 & -94.5 & - \\
\hline Drought 2 & -44.0 & - & - \\
\hline MwMet & - & -48.5 & - \\
\hline
\end{tabular}

Table 5. Dunnett's values from ambient temperature mean comparisons at the 99\% level, Lengwe National Park. Negative values: pairs are not significant

\begin{tabular}{|lccc|}
\hline Scenario & $\begin{array}{c}\text { Baseline scenario control } \\
\text { M wMet }\end{array}$ & $\begin{array}{c}\text { Climate change scenario control } \\
\text { Drought 2 }\end{array}$ & M wM et \\
\hline CCC & 1.3 & -2.1 & 0.04 \\
UK89 & 0.5 & -1.5 & 0.6 \\
GFD3 & -4.1 & -2.2 & -0.1 \\
Drought 1 & -2.9 & -3.1 & - \\
Drought 2 & -2.4 & - & - \\
MwMet & - & -1.9 & - \\
\hline
\end{tabular}

Precipitation distribution $\left(\mathrm{mm} \mathrm{d}^{-1}\right)$ under Drought 2 was lower than under Drought 1, but was higher than those obtained by the 3 climate scenarios (Fig. 4). The differences in precipitation distribution are not significant at the $99 \%$ level between the different data setsthat is, Drought 2 versus Drought 1 and the climate change scenarios. The distribution pattern throughout the year, however, was worst during Drought 2. There was no precipitation from J une to October in Drought 2 , while there was some during Drought 1; the climate change scenarios predict that there will be some precipitation during this period (Fig. 4). Monthly precipitation was lower throughout Drought 2 than the amount of evaporation (Fig. 3).

The mean annual temperatures were lower under the drought events than those predicted by the GCM s (Table 3). The differences in temperature rise among Drought 2, Drought 1 , and the climate change scenarios might not be so large (Table 5).

\subsection{Herbaceous layer productivity, ground cover, and browse utilisation}

Drought 2 reduced herbaceous layer productivity drastically (Table 6). Independent of any off-take, the productivity was 2 and 6 times lower in 1992 than during the normal rainy seasons, i.e. 1989 and 1990 respectively. The off-take was also correspondingly lower in 1992 than in the seasons preceding the drought.

The drought reduced the ground cover drastically as evidenced by the high relative frequency of bare ground in both seasons (Fig. 5). The mean basal cover was $32 \pm 23.3$ and $22.9 \pm 21.1$ in the late rains and early dry season, respectively. However, a decline was significant over the seasons.

More plants were intact and lightly browsed than intensely or severely browsed during the late rains (Table 7). A similar pattern is apparent during the early dry season. During the early dry season, more plants were browsed than in the late rains. However, there were more plants in the b0 and bl categories than in b2 and b3.

\section{DISCUSSION}

Temperature, precipitation, and soil moisture are important in the primary production of natural ecosystems. As these would change because of global warming, to assess the likely impacts of climate change inferred from the GCM models and observed climate and drought is sensible.

The increases in temperature and precipitation in southern Africa as a result of doubling carbon dioxide in the atmosphere have been reported in the studies of M agadza (1994), Hulme (1996), and Unganai (1996), to mention just a few. This study and the previous one for the same site (M kanda 1996) concur with the findings of the other investigators. It should be expected that the study area will become wetter (albeit not significantly) than it is under the current climate, if the climate change conditions occur as the UK89 and GFD3 models predicted (Tables $2 \& 3$ ). However, the high temperatures will possibly diminish the effects of increased precipitation. Since there are no significant differences between temperature and precipitation between Drought 2 and all 3 GCM climate change scenarios (Tables $4 \& 5$ ), it can be contended that evapo-

Table 6. Herbaceous layer productivity and off-take ( $\left.\mathrm{kg} \mathrm{ha}^{-1}\right)$ in Acacia nigrescens and Albizia harveyi/Ziziphus mucronata in the late rains, Lengwe National Park

\begin{tabular}{|ccc|}
\hline Year & Productivity & Off-take \\
\hline 1989 & 480 & 11.6 \\
1990 & 170.0 & 17.0 \\
1992 & 75.7 & 5.6 \\
\hline
\end{tabular}




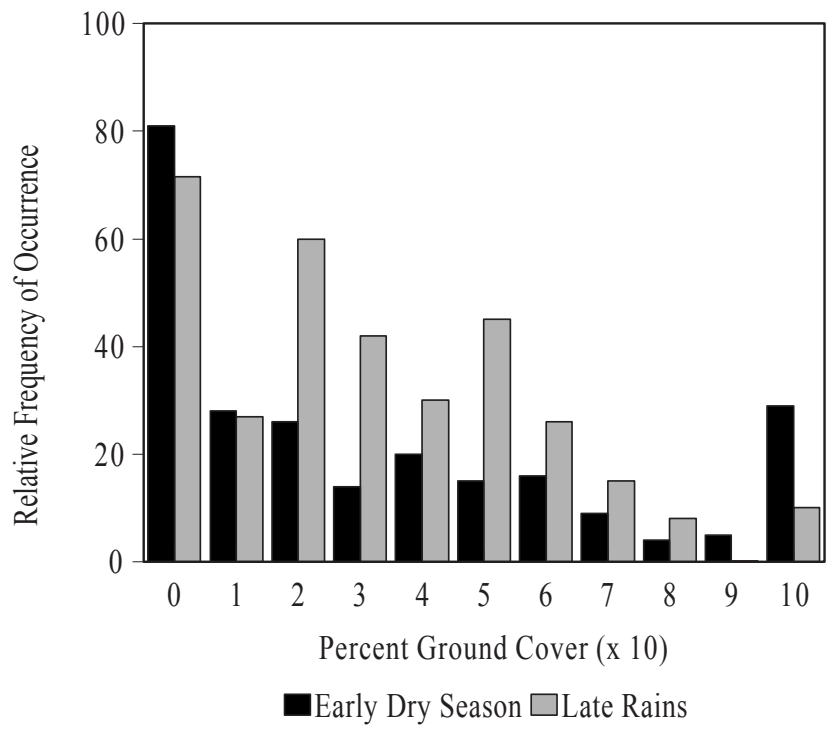

Fig. 5. Ground cover relative frequency of occurrence during Drought 2, Lengwe National Park

ration rates that are higher than precipitation as recorded during Drought 2 (Fig. 3) will prevail under climate change. Under such conditions, soil moisture would be deficient. The study therefore agrees with Hulme et al. (1994), who postulated that the significant increases in ambient temperatures would probably increase evapotranspiration rates, reduce water availability, and reduce vegetation productivity. Walker et al. (1987) also observed that precipitation influenced vegetation productivity and ground cover in various wildlife reserves in southern Africa.

Being the primary food resource and habitat for animals, vegetation is essential for conservation of wild life in the park. The high evaporation rates observed under Drought 2 are liable to occur or become permanent under climate change. Such a situation would not only limit vegetation productivity, but also affect animal biomass negatively. Coe et al. (1976) and Western (1991) have shown that there is a positive correlation between animal biomass, vegetation productivity, and precipitation. The reduction in herbaceous layer productivity and low off-take observed under Drought 2 in Lengwe illustrate that, indeed, low precipitation would not support high animal biomass in the park.

The reduction in ground cover during the 1991/92 drought has adverse consequences for habitat suitability. Bare ground is subject to high surface runoff and resultant soil erosion. Erosion adversely affects soil quality and productivity by reducing infiltration rates, water-holding capacity, nutrients, organic matter, soil biota, and soil depth (El-Swaify et al. 1985, Troeh et al. 1991). In the tropics, Lal (1976) reported that erosion may reduce infiltration by up to $93 \%$. Low productivity because of low precipitation, high temperature, and high evaporation would lead to poor ground cover and soil degradation. In turn, soil degradation would lead to low productivity, hence low habitat suitability. It would appear then that such a vicious cycle is probable under climate change conditions. Magadza (1994) used a drought analogue scenario to question the continued capability of the savannahs, particularly those of east and southern Africa, to support huge populations of large mammals. This study concurs with this concern.

There was speedy regrowth as more woody plants were lightly browsed or untouched during both the late rains and early dry season. Vesey-FitzGerald (1973) indicated that a bl plant is not greatly harmed and any damage is speedily replaced by growth. A b2 plant is also replaceable by growth, although the stature and shape of the plant may be reduced or modified by continued browsing. It was also indicated that b2 impact is the most important category to monitor in assessing the supply and use of browsable vegetation. The increase in the number of plants in the b2 category insinuates that the impact progressed from the late

Table 7. Number of species, plants sampled, and browse impact in vegetation communities, Lengwe National Park, 1992. Vegetation community codes: $\mathrm{A} h=$ Albizia harveyi, A n1 = Acacia nigrescens thicket clump savannah, A n2 = Acacia nigrescens/Dalbergia melanoxylon tree savannah, A n3 =Acacia nigrescens/Ziziphus mucronata tree savannah, A n4 = Acacia nigrescens tall tree savannah, A n5 = A cacia nigrescens savannah woodland, D $\mathrm{m}=$ Dalbergia melanoxyIon tree savannah, I b = Ischaemm brachyatherum grassland dambo, P I = Pterocarpus lucens. b0-b3: levels of browse impact (see Section 2.5)

\begin{tabular}{|c|c|c|c|c|c|}
\hline \multirow[t]{2}{*}{ Season } & \multirow{2}{*}{$\begin{array}{l}\text { Vegetation } \\
\text { community }\end{array}$} & \multicolumn{4}{|c|}{ No. of plants } \\
\hline & & b0 & b1 & b2 & b3 \\
\hline \multirow[t]{9}{*}{ Late rains } & $\mathrm{A} \mathrm{h}$ & 17 & 7 & 40 & 0 \\
\hline & A n1 & 48 & 14 & 45 & 0 \\
\hline & A n 2 & 44 & 5 & 36 & 0 \\
\hline & A n3 & 31 & 5 & 10 & 0 \\
\hline & A n4 & 7 & 2 & 6 & 0 \\
\hline & A n5 & 6 & 5 & 5 & 0 \\
\hline & $\mathrm{D} \mathrm{m}$ & 4 & 1 & 3 & 0 \\
\hline & I b & 7 & 0 & 1 & 0 \\
\hline & $\mathrm{PI}$ & 4 & 0 & 3 & 0 \\
\hline Total & & 168 & 39 & 149 & 0 \\
\hline \multirow[t]{9}{*}{ Early dry } & $\mathrm{A} \mathrm{h}$ & 31 & 39 & 25 & 0 \\
\hline & A n1 & 123 & 121 & 119 & 29 \\
\hline & A n 2 & 60 & 38 & 59 & 10 \\
\hline & A n3 & 32 & 12 & 19 & 1 \\
\hline & A n4 & 29 & 21 & 14 & 0 \\
\hline & A n5 & 25 & 7 & 8 & 0 \\
\hline & $\mathrm{D} \mathrm{m}$ & 1 & 6 & 12 & 5 \\
\hline & I b & 12 & 0 & 4 & 0 \\
\hline & $\mathrm{PI}$ & 23 & 20 & 16 & 4 \\
\hline Total & & 336 & 264 & 276 & 49 \\
\hline
\end{tabular}


rains to the early dry season. Most likely, it continued increasing in the late dry season.

Unlike in Drought 1 when nyala mortality occurred, there was no mortality during Drought 2 . Since there is no significant difference in precipitation and temperature between Drought 1 and Drought 2, the absence of animal mortality during Drought 2 was due to the fact that the nyala population had been reduced through culling (M kanda \& M unthali 1991).

Variations in large mammal populations have occurred because of gradual aridification of the Chobe wetlands (Magadza 1994). During the Quaternary period, climate change resulted in geological redistribution of micro-mammalian fauna of southern A frica, as ecologically preferred zones for various assemblages changed their geographical ranges (Thackeray 1987). Franklin (1980) stated that a species that is vulnerable to capricious events is likely to be so because it has, in the past, adapted less well than its competitors to a changing environment. The nyala and other species in Lengwe have been subjected to harsh climate, hence they are likely to be adapted less well than those not subjected to similar conditions. Since drought episodes, as analogue climate scenarios, illustrate that vegetation productivity declines, the variations in large mammal populations and redistribution of micro-fauna observed elsewhere might act as a lesson specifically for Lengwe, but possibly in other wildlife conservation areas in Malawi as well.

\section{CONCLUSIONS}

Ambient temperature and precipitation in Lengwe National Park will probably increase under climate change. It appears that the conditions will be similar to those observed during the 1991/92 drought-namely, high temperature and evaporation rates. The consequences will be low vegetation productivity that would likely lead to habitat degradation. Consequently, the habitat would be unable to sustain a high population of large mammals.

\section{LITERATURE CITED}

Anonymous (1975) An atlas of the Shire Valley. Department of Surveys, Blantyre

Boer GJ , M CFarlane NA, Lazaro M (1992) Greenhouse gasinduced climate change simulated with the CCC second generation general circulation model. Bull Am Meteorol Soc 5:1045-1077

Carter TR, Parry ML, Harasawa H, Nishioka S (1994) Intergovernmental Panel on Climate Change technical guidelines for assessing climate change impacts and adapta- tions. University College London and Centre for Global Environmental Research, London

Coe MJ , Cumming DHM, Phillipson J (1976) Biomass production of African herbivores in relation to rainfall and primary production. Oecologia 22:341-354

El-Swaify SA, Moldenhauer WC, Lo A (1985) Soil erosion and conservation. Soil Conservation Society of America, Ankeny, IA

Franklin IR (1980) Evolutionary change in small populations. In: Soulé ME, Wilcox A (eds) Conservation biology: an evolutionary-ecological perspective. Sinauer Associates Inc, Sunderland, MA

Hall-M artin AJ (1972) Aspects of the plant ecology of Lengwe National Park, Malawi. MSc thesis, University of Pretoria

Hulme M (1996) Climate change and Southern Africa: an exploration of some potential impacts and implications in the SADC region. Climatic Research Unit, University of East Anglia, and World Wide Fund International, Gland

Hulme M, Conway D, Kell PM, Subak S, Downing TE (1994) The impacts of climate change on Africa. Centre for Social and Economic Research on the Global Environment Working Paper GEC 95-04. University of East Anglia, Norwich

Kamvazina BS (1981) Nyala culling and capture report, Lengwe National Park. Department of National Parks and Wildlife, Lilongwe

Lal R (1976) Soil erosion problems on an alisol in western Nigeria and their control. International Institute of Tropical Agriculture, Ibadan

Magadza CHD (1994) Climate change: some likely multiple impacts in southern Africa. Food Policy 19(2):165-191

Manabe S, Wetherald RT (1987) Large scale changes in soil wetness induced by an increase in carbon dioxide. J Atmos Sci 44:1211-1235

M itchell J FB, Senior CA, Ingram WJ (1989) $\mathrm{CO}_{2}$ and climate: a missing feedback. Nature 341:132-134

M kanda FX (1996) Potential impacts of future climate change on nyala Tragelaphus angasi in Lengwe National Park, Malawi. Clim Res 6:157-164

M kanda FX, M unthali SM (1991) M ortality of nyala (Tragelaphus angasi G) in Lengwe National Park, Malawi. Afr J Ecol 29:28-36

Mueller-Dombois D, Ellenberg H (1974) Aims and methods of vegetation ecology. J ohn Wiley and Sons, Inc, New York

M unthali SM (1991) The feeding habits of nyala (Tragelaphus angasi) in Lengwe National Park, Malawi. Nyala 12(1): 17-23

Sall J, Lehman A (1996) J MP start statistics - a guide to statistical and data analysis using J M P and J M P IN software. Duxbury Press, New York

Thackeray J F (1987) Late quaternary environmental changes inferred from small mammalian fauna, Southern Africa. Clim Change 10:285-305

Troeh FR, Hobbs J A, Donahue RL (1991) Soil and water conservation. Prentice-Hall, Englewood Cliffs, NJ

Unganai LS (1996) Historic and future climatic change in Zimbabwe. Clim Res 6:137-145

Vesey-FitzGerald D (1973) Browse production and utilisation in Tarangire National Park. E Afr Wildl J 11:291-305

Walker BH, Emslie RH, Owen-Smith RN, Scholes RJ (1987) To cull or not to cull: lessons from a southern A frican drought. J Appl Ecol 24:381-401

Western D (1991) Climatic change and biodiversity. In: Ominde $\mathrm{SH}$, J uma $\mathrm{C}$ (eds) $\mathrm{A}$ change in the weather. African Center for Technology Studies, Nairobi, p 87-96 